\title{
An Analysis of Enhancing User Stickiness of Group Purchase Websites
}

\author{
Yanling Tang ${ }^{\mathrm{a}}$, Ying Wang \\ School of Foreign Languages, Changchun Institute of Technology, Jilin 130012, China; \\ atangyanling_bird@yahoo.com
}

Keywords: group purchase, users stickiness, internet, management.

\begin{abstract}
As a new member of the electronic commerce, network group purchase provides users with a more convenient, affordable and innovative consumption pattern, as well as a more direct and effective mode to the business. Since the first domestic group purchase website---www.meituan.com was founded in March 2010, network group purchase market has entered a rapid development period and the number of it is also rising up sharply. However, due to keen competition and non-standard operation in current network group purchase industry, user problems of group purchase websites have become increasingly prominent.In particular, the performance of group purchase websites fails to meet users' expectation in terms of maintaining users. Therefore, how to enhance user stickiness of group purchase websites becomes a subject which is worthy of study under the fierce competition in network group purchase market. This paper will give a literature review of network group purchase, and then it will analyze some reasons of insufficient user stickiness. Based on those reasons, factors of increasing user stickiness will be discussed. Finally, some effective solutions will be put forward. Actually, the purpose of this paper is to give some constructive suggestions to group purchase websites for enhancing their user stickiness, and hoping to promote further development of national group purchase websites.
\end{abstract}

\section{Introduction}

In November 2008, GROUPON, the first professional group purchase websites, was put into operation in the Unites States. And in its first year, it created a \$1.36 billion turnover. The successful mode of GROUPON attracted the attention of domestic entrepreneurs and investors immediately, and soon the first domestic professional group purchase website named Meituan net was founded in April 2010. Since then, the domestic network group purchase market is detonated and the uncontrollable growth appears. Afterwards, number of websites had been rising sharply and the considerable volume of transactions had been created. And the whole group purchase industry was in thriving situation.

Because of its onefold profit pattern, keen competition and lack of relative effective supervision, the network group purchase industry is suffering from "Growing Pains" now, many websites face with closure or transition. Even so, the numbers of group purchase websites is still more than 3600 by the end of February this year.

Although the development of network group purchase market is in sound momentum, many problems to be solved have been already appeared in most of group purchase websites because of keen competition in network group purchase industry. For group purchase websites, they have to face these problems instead of skirting round or skirted round skirt roundskirt roundworking half-heartedly in order to stand out from the competition.

\section{Problems of Group Purchase Websites in User Stickiness}

"User stickiness is an attribute of group purchase websites, and it is usually used to describe the ability that websites attract visitor, retain visitors and prolong their residence time. From point of the visitor, user stickiness is similar to the meaning of customer loyalty. It is an intangible ability to keep the visitors returned for many times over long periods of time."[1]

However, some related research show that the rate of second glance of group purchase websites is not satisfactory, though network group purchase has achieved rapid development. That's to say, the 
user stickiness of group purchase websites is generally poor. The reasons of it can be roughly attributed to the following aspects.

(1) Deficient products

In network group purchase activities, these sites play the role of intermediaries, which is responsible for presenting products and attracting users. Because of the keen competition and immature manipulation in network group purchase industry, products presented in the websites are not in line with those of actual consumption, which will make users generate dissatisfaction with the websites. Consequently, group purchase websites lose these users. In addition, the success of purchase in group purchase websites is determined by the quantities which in turn could cut down the cost of business, actually, it may be beyond the capacity of some business, especially for catering and entertainment industry. So, users cannot enjoy equal treatment with other normal consumers[2], Besides, comparing to the varieties of products in traditional retail store, species of products in group purchase websites are obviously limited, which will greatly affect users' purchase behavior, or rather, users' stickiness..

(2) Unavailable service

According to the data conducted by some related research, it is found that the service of group purchase websites is always unavailable. Many group purchase websites fail to carry out their stated commitments. For instance, the demonstration that transaction can be conducted at any time by means of order is usually broken by business in real practice. What' s worse, for problems proposed by users, group purchase websites usually work half-heartedly or shift the responsibilities to business. It is a typical example that the business takes responsibility for the quality of the goods or service while the website has no obligation.

(3) Inconvenient and unattractive web design

At present, many domestic group purchase websites follow the Groupon in design of their websites, which leads to serious homogenization in network group purchase industry. Because many homogeneous group purchase sites exist at the same time, it is hard to attract more attention of users. Based on the observation, it is revealed that domestic group purchase websites just imitate the GROUPON' s interface form and operation mode. As for the program structure and optimization of web design, domestic group purchase websites are in a complete mess, which lead to inconvenience for users in purchase.

(4) Unguaranteed safety

Because of the unique pattern that payment is made before consumption, most of group purchase websites require their users to pay for the goods in advance by Alipay and online bank rather than to complete payment after satisfactory consumption. Network group purchase is just the beginning of the whole transaction and it will be ended till users' consumption in business. During this process, once problems occur or refund needs to be done, some sites often make excuses such as problems with Alipay and attack of sites to delay withdrawals, which adds a hidden danger to the user's security of refund. Besides, because most group purchase websites do not make a enough investment in security or even ignore it, there may be some leaks in them. However, the users believe in them, and then they submit necessary information including their private information such as address and telephone number. But, once group purchase websites suffer from malicious attacks, users' personal information may be leaked, which makes their users suffer from losses as a result. For instance, according to the clues provided by a user, users' data of a well-known group purchase websites had been compromised and widely spread on P2P. Once this information is being misused, the consequences will be unimaginable.

\section{Solutions to Enhancing User Stickiness in Group Purchase Websites.}

In order to maintain good and long-term development, group purchase websites have to solve these existing problems. Based on the factors analyzed above, the solutions to enhancing user stickiness are as follows. 
(1 )Perfecting web design and ensuring private information safe

Group purchase websites should perfect their navigation and improve the retrieval speed, so that users can purchase favorable goods easily and happily, as well as save their time. In terms of perfecting web design, group purchase websites can set multi-level navigation menus and layering prompting message according to distinguish functions. At the same time, the interface of group purchase websites must respect users' browsing habits, which will improve its friendliness and operability. Besides, artistic design of interface should be done to make users feel comfortable, so as not to distract their attention. To protect the security of users' delivery information, group purchase websites can recruit high quality professional talents to write code of their application procedure, which can greatly avoid program vulnerabilities and hacker's attack. In addition, group purchase websites should established a complete network alarm system. Once the abnormal happens, it will alarm to catch personnel's attention and some actions will be taken to ensure their private information safe.

(2) Choosing high-quality business and strengthening the supervision

The goods and service quality of a business have a great impact on the user stickiness of group purchase websites. In order to ensure the quality of goods and service, the websites should prefer to cooperate with high-quality business directly with the principle of transparency and openness. When choosing high-quality business, group purchase websites should strictly adhere to examination and approval mechanism. In case that group purchase websites tend to cooperate with business with poor credibility and low visibility, they need to make an on-the-spot investigation into the goods, environment, service quality and reception capacity etc, for making sure that users can be satisfied. Otherwise, once related problems appear, group purchase websites will bear the joint liability and make appropriate compensation. Meanwhile, group purchase websites should strengthen supervision on business. When entering into an agreement with a business, group purchase websites should have clear obligations of businesses under certain constraints. And based on these obligations, group purchase websites should also supervise the goods quality and service attitude business actually offered to prevent the existence of disguised price, so as to make users enjoy their consumption successfully.

(3) Improving after-sales service quality

In network group purchase activities, satisfaction of users is closely bound up with the after-sales service quality, which will greatly influence the user stickiness of group purchase websites. Therefore, group purchase websites should enhance their after-sales service quality. On one hand, they should improve the convenience of their after-sales service, which can be achieved by the following two ways.

Firstly, to build online service platform and increase the number of after-sales service personnel with a good attitude of service. Thus, users can get after-sales service anywhere and anytime.

Secondly, group purchase websites should increase the speed of dealing with complaints of users. On the other hand, they should enhance the effectiveness of their after-sales service in the following ways. It is to clear terms of service and give effective solutions to the problems users complained instead of shifting the responsibilities or work half-heartedly[3]. For instance, they should pay money back to users according with withdrawal provision rather than take up users' money.

(4) Optimizing goods and enriching species

Because different user groups usually have different demands for goods, group purchase websites should firstly choose their target users. For target users, the optimization of goods should be supposed to be based on the features of the users[4], which will not only increase the purchase rate of goods, but also increase the user stickiness on the sites, eventually creating a better recurring atmosphere of group purchase. For instance, for female users formed by group purchase of facial mask, the team of OPTICSKY contacts a perfume product business right away. As soon as the perfume is brought out in its sub-website, a great sensation is caused and a good performance is also created afterwards. In addition, the existing group purchase mode is to provide one or a few goods each day, which has greatly limited users' visits. Thus, group purchase websites should organize a professional team to expand business and enrich goods. Although the number of goods is in rapid growth in group 
purchase websites, species of goods are much less when compared with the traditional shopping. So group purchase websites should frequently analyze species of presenting goods and then develop new products to cover more areas.

(5) Strengthening the interaction

Group purchase website should work at in-depth interaction with the users and try hard to attract them through launching various online and offline activities by the way of neck to neck[5]. For online activities they may develop new users well and enhance user stickiness on the sites. Offline activities can effectively catch users' eyes and draw public attention and increase the rate of notability of sites as well. Meanwhile, group purchase websites should also establish an assessment system, in which users give their judgments of goods after their consumption. Comparing with the common information compiled carefully by an editor, information in the assessment system is edited by the users who have actual consumption experience. So there is more authenticity and greater reference value of the information provided by the third parties. The more assessment, the stronger interaction. Naturally, the user stickiness of sites will also be enhanced. Furthermore, the assessment system can also be an indirect supervision to business on their service quality. Based on the assessment, group purchase websites should give up some business with too much bad assessment, optimizing their products and improving users' satisfaction. Only in this way can user stickiness be enhanced.

\section{Summary}

The paper given the literature review of network group purchase and studied the user stickiness of group purchase websites. The reasons of insufficient user stickiness were found through an analysis of problems of group purchase websites. Based on those reasons, it summed up factors that increase user stickiness, and then suggestions were provided. The purchase of this paper is to identify reasons of insufficient user stickiness of group purchase websites and analyze factors of enhancing user stickiness. And based on the above, it put forward with related solutions. Hoping this article will help group purchase websites enhance their user stickiness and grow better.

In addition, the research of user stickiness in group purchase websites is still in its infancy, and related theories are not mature enough. And because of my limited capacity, this study has some points that are not perfect. But, the author hopes that this paper will benefit for people who still study user stickiness of group purchase websites in the future.

\section{Acknowledgements}

The authors would like to give their thanks to Jilin Social Science Foundation (NO.2014wy23) and Changchun Institute of Technology for their financial and technical support.

\section{References}

[1]. Jesse James Garrett. The Elements of User Experience. New Riders Press, 2002,p10-11

[2]. Jagdish N. Sheth, Banwari Mittal. Customer Behavior. South-Western College Pub, 2003.p5-7

[3]. Lu Dong. The loyalty of consumers should be set up by E-business. Research Center of E-commerce in China, 2011, 9 , p.25-27.

[4]. Wanzhen Wang. On Women's Psychology of Consumption in Marketing. Fujian Administration College, 2005, 11, p25-26

[5]. Group purchase http://einovo.cool.blog.163.com/blog/static/1113197402009103023011413/, 2011.11. 